Closed-Shell Organic Compounds Might Form Dimers at the Surface of Molecular Clusters

Hirvonen, Viivi

2018-02-15

Hirvonen , V , Myllys , N , Kurtén , T \& Elm , J 2018 , ' Closed-Shell Organic Compounds Might Form Dimers at the Surface of Molecular Clusters ', Journal of Physical Chemistry A , vol. 122 , no. 6 , pp. 1771-1780 . https://doi.org/10.1021/acs.jpca.7b11970

http://hdl.handle.net/10138/271658

https://doi.org/10.1021/acs.jpca.7b11970

acceptedVersion

Downloaded from Helda, University of Helsinki institutional repository.

This is an electronic reprint of the original article.

This reprint may differ from the original in pagination and typographic detail.

Please cite the original version. 


\title{
Closed-shell Organic Compounds Might Form Dimers at the Surface of Molecular Clusters
}

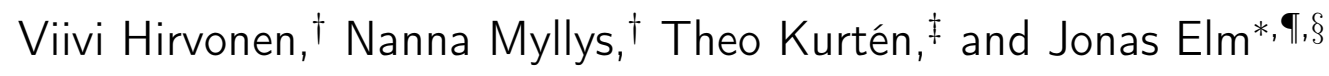 \\ Department of Physics, University of Helsinki, Finland, Department of Chemistry, \\ University of Helsinki, Finland, and Department of Chemistry, Aarhus University, \\ Denmark.
}

E-mail: jelm@chem.au.dk

\footnotetext{
*To whom correspondence should be addressed

${ }^{\dagger}$ University of Helsinki

$\ddagger$ University of Helsinki

"Aarhus University

$\S+4528938085$
} 


\begin{abstract}
The role of covalently-bound dimer formation is studied using high-level quantum chemical methods. Reaction free energy profiles for dimer formation between common oxygen-containing functional groups are calculated, and based on the Gibbs free energy differences between transition states and reactants, we show that none of the studied two-component gas-phase reactions are kinetically feasible at $298.15 \mathrm{~K}$ and 1 atm. Therefore, the catalysing effect of water, base, or acid molecules is calculated, and sulfuric acid is identified to lower the activation free energies significantly. We find that the reactions yielding hemiacetal, peroxyhemiacetal, $\alpha$-hydroxyester, and geminal diol products occur with activation free energies of less than $10 \mathrm{kcal} / \mathrm{mol}$ with sulfuric acid as a catalyst, indicating that these reactions could potentially take place on the surface of sulfuric acid clusters. Additionally, the formed dimer products bind stronger onto the pre-existing cluster than the corresponding reagent monomers do. This implies that covalent dimerization reactions stabilize the existing cluster thermodynamically and make it less likely to evaporate. However, the studied small organic compounds, which contain only one functional group, are not able to form dimer products which are stable against evaporation at atmospheric conditions. Calculations of dimer formation onto a cluster surface and the clustering ability of dimer products should be extended to large terpene oxidation products in order to estimate the real atmospheric significance.
\end{abstract}




\section{1 - Introduction}

Atmospheric aerosol particles have a profound impact on global climate change, regional air quality, and human health. ${ }^{1,2}$ A significant fraction of aerosol particles is formed via gas-to-particle conversion. ${ }^{3}$ In urban areas, secondary organic aerosols (SOAs) comprise up to $90 \%$ of the total organic aerosol mass. ${ }^{4,5}$ However, the molecular-level mechanisms and participating compounds leading to SOA formation remain highly uncertain. ${ }^{6}$ Newparticle formation is believed to occur through a clustering mechanism, involving sulfuric acid coupled with a stabilizing component such as bases and oxidized organic compounds. ${ }^{7-12}$ Experimental studies have suggested that highly oxidized multifunctional organic compounds (HOMs) are participating in the first steps of new-particle formation, but the chemical identity of the proposed species remain unknown. ${ }^{13,14}$

Using computational methods, we have previously studied cluster formation between sulfuric acid and a highly oxidized $\mathrm{C}_{6} \mathrm{H}_{8} \mathrm{O}_{7}$ ketodiperoxy acid originating from autoxidation of cyclohexene. It was discovered that autoxidation products containing only peroxyacid, hydroperoxide, and carbonyl groups are not able to enhance the new-particle formation process. ${ }^{15}$ This implies that oxygen-to-carbon ratio cannot solely be used as a proxy for volatility and the ability to form clusters with sulfuric acid. ${ }^{16,17}$ The number of hydrogen bonding groups and the specific molecular structure offer a better metric for the determination of the strength of intermolecular interactions. Using computational methods, we recently studied the specific requirements for oxidized organic compounds to act as a stabilizer in sulfuric acid induced clustering, and concluded that organic compounds containing multiple carboxylic acid groups are the most prominent candidates in atmospheric cluster formation. ${ }^{18}$ Using high-level quantum chemical methods together with kinetic calculations, we demonstrated that tricarboxylic acids and sulfuric acid, even together with other stabilizing compounds such as ammonia or ions, cannot drive the observed new-particle formation events via clustering mechanisms. ${ }^{19}$ Combined these theoretical studies suggest that other compounds or mechanisms are needed to explain experimentally measured formation events. ${ }^{20}$ 
It has been shown both in field and smog chamber measurements that SOAs contain oligomeric macromolecules, which might be formed in either gas- or particle-phase reactions. ${ }^{21-26}$ However, the reaction kinetics of covalently-bound dimer and higher order oligomer formation as well as the relative significance of participating vapours are unknown. So called accretion reactions have been proposed to be a part of the formation of organic particulate matter. ${ }^{27-29}$ Accretion reactions include a variety of different reactions, e.g. oligomerization, hydration, and aldol condensation, where organic molecules can increase their molecular weight, thus reducing their volatility. In addition, the dimer products could potentially be formed via radical pathways, e.g., radical-radical recombination has been suggested. ${ }^{30}$ In this article, we have focused on possible atmospherically relevant dimerization reactions between closed-shell molecules. Here, dimers are defined as large molecules formed by the coupling of two "monomer" oxidation products. Due to a large number of different monomers present in the gas-phase, there exists a plethora of possible dimer products. ${ }^{31-36}$ Consequently, theoretical investigations are needed to augment experimental studies and to probe the detailed reaction mechanisms of dimer formation, and its impact on atmospheric new-particle formation and growth.

Computationally, covalently-bound dimer formation and the effect of different catalysts has been researched using mainly semi-empirical or DFT methods. For example, the aldol condensation product has been suggested to be a thermodynamic sink for methylglyoxal dimerization, ${ }^{37}$ and peroxyhemiacetal formation from $\alpha$-pinene oxidation products have been proposed. ${ }^{38}$ However, since the transition states tend to be high in energy for reactions between closed-shell molecules, ${ }^{39-43}$ the effect of different catalysts in atmospherically relevant reactions should be taken into account. Formic acid has been shown to decrease activation energies for the hydration of formaldehyde, acetaldehyde, and glyoxal, ${ }^{44-46}$ and sulfuric acid to catalyse hydration reactions. ${ }^{47,48}$.

Using a variety of computational tools, we investigate the kinetics and thermodynamics of covalently-bound dimer formation reactions between common organic functional groups 
(alcohols, carboxylic acids, peroxides, peroxy acids and oxo groups). The effect of different catalysts on reaction energetics is also addressed. We wish to explore the possibility of covalently-bound dimer formation reactions occurring in atmospheric conditions, both in the gas-phase and at the particle interface.

\section{2 - Methods}

All geometry optimizations and vibrational frequency calculations were carried out using the Gaussian09 and Gaussian16 program packages. ${ }^{49,50}$ Single point energy evaluations were run using the Orca 4.0.0.2. program. $^{51}$ Thermochemical parameters are calculated using standard rigid rotor and harmonic oscillator approximations, and all values are reported in $\mathrm{kcal} / \mathrm{mol}$ at $298.15 \mathrm{~K}$ and $1 \mathrm{~atm}$. All transition states were characterized by visual inspection and one imaginary frequency corresponding to the reaction coordinate.

For geometry optimizations and thermochemical parameters, the $\omega$ B97X-D functional ${ }^{52,53}$ with the $6-31++\mathrm{G}^{* *}$ basis set were utilized. ${ }^{54-56}$ This long-range corrected hybrid functional includes empirical atom-atom dispersion corrections, and has been shown to yield good accuracy for kinetics, thermodynamics, and non-covalent interactions. ${ }^{57}$ The small $6-31++\mathrm{G}^{* *}$ basis set has been shown to be sufficient for obtaining the geometries and vibrational frequencies of atmospheric relevant clusters. ${ }^{58,59}$ In order to obtain more accurate Gibbs free energies, we calculated electronic energy corrections on top of the DFT geometries using a domainbased local pair natural orbital coupled cluster method (DLPNO-CCSD(T)) ${ }^{60-62}$ with an aug-cc-pVTZ basis set ${ }^{63,64}$ and tight pair natural orbital (TightPNO) criteria. DLPNO$\operatorname{CCSD}(\mathrm{T})$ has been demonstrated to yield results close to the canonical coupled cluster level of theory at significantly lower computational costs. ${ }^{65}$

To ensure the sufficiency of the chosen level of theory, we have utilized the MP2 method with aug-cc-pVTZ basis set in addition to DFT for geometry optimization and thermochemical parameters. Furthermore, the DLPNO-CCSD $(\mathrm{T}) /$ aug-cc-pVTZ method is benchmarked 
against a high-level explicitly correlated coupled cluster RI-CCSD(T)-F12 ${ }^{66-68}$ method with double, triple, and quadruple zeta basis sets $\left(\mathrm{V} n \mathrm{Z}-\mathrm{F} 12^{69}\right)$. One cardinal number higher basis set was used for Coulomb fittings within the RI approximation, e.g. for cc-pVTZ-F12, the auxiliary basis is cc-pVQZ/C. Throughout the paper we will refer to RI-CCSD(T)-F12/VnZF12, DLPNO-CCSD(T)/aug-cc-pVTZ, MP2/aug-cc-pVTZ and $\omega$ B97X-D/6-31++G(d,p) simply as F12/VnZ, DLPNO, MP2 and DFT, respectively.

The approximate DLPNO Gibbs free energy value is calculated as:

$$
G^{\mathrm{DLPNO} *}=E^{\mathrm{DLPNO}}+G_{\text {thermal }}^{\mathrm{DFT}}
$$

where $E^{\text {DLPNO }}$ is the single point energy (SPE) calculated using DLPNO, and $G_{\text {thermal }}^{\mathrm{DFT}}$ the thermal contribution to the Gibbs free energy obtained with DFT. The activation free energy describes how much energy is needed to form the transition state starting from the reactants, and it determines the reaction rate. It is calculated as the following:

$$
\Delta G^{\ddagger}=G^{\mathrm{TS}}-G^{\mathrm{R}}
$$

where $G^{\mathrm{TS}}$ and $G^{\mathrm{R}}$ are the Gibbs free energies of transition state and isolated reactants, respectively. The reaction free energy tells where the thermodynamic equilibrium lies, and it is calculated as:

$$
\Delta G_{\text {reac }}=G^{\mathrm{P}}-G^{\mathrm{R}}
$$

where $G^{\mathrm{P}}$ corresponds to the Gibbs free energy of the products. For a given reaction to be feasible in the gas-phase, the activation free energy has to be sufficiently low for the reaction to occur and the reaction free energy has to favour the products.

In this paper we have studied several different reactions involving the carbonyl group of 
either formaldehyde $\left(\mathrm{H}_{2} \mathrm{CO}\right)$ or formic acid $(\mathrm{HCOOH})$ :

$$
\begin{aligned}
& \mathrm{H}_{2} \mathrm{CO}+\mathrm{CH}_{3} \mathrm{OH} \rightarrow \mathrm{CH}_{3} \mathrm{OCH}_{2} \mathrm{OH} \\
& \mathrm{H}_{2} \mathrm{CO}+\mathrm{CH}_{3} \mathrm{OOH} \rightarrow \mathrm{CH}_{3} \mathrm{O}_{2} \mathrm{CH}_{2} \mathrm{OH} \\
& \mathrm{H}_{2} \mathrm{CO}+\mathrm{HCOOH} \rightarrow \mathrm{HCO}_{2} \mathrm{CH}_{2} \mathrm{OH} \\
& \mathrm{H}_{2} \mathrm{CO}+\mathrm{HCOOOH} \rightarrow \mathrm{HCO}_{3} \mathrm{CH}_{2} \mathrm{OH} \\
& \mathrm{H}_{2} \mathrm{CO}+\mathrm{H}_{2} \mathrm{O} \rightarrow \mathrm{CH}_{2}(\mathrm{OH})_{2} \\
& \mathrm{HCOOH}+\mathrm{CH}_{3} \mathrm{OH} \rightarrow \mathrm{CH}_{3} \mathrm{OCH}(\mathrm{OH})_{2} \rightarrow \mathrm{CH}_{3} \mathrm{OCHO}+\mathrm{H}_{2} \mathrm{O} \\
& \mathrm{HCOOH}+\mathrm{HCOOH} \rightarrow\left(\mathrm{H}_{2} \mathrm{COH}\right)_{2} \mathrm{O} \rightarrow(\mathrm{HCO})_{2} \mathrm{O}+\mathrm{H}_{2} \mathrm{O}
\end{aligned}
$$

Reactions R1 and R2 correspond to the simplest hemiacetal and peroxyhemiacetal formations, respectively. Hemiacetal (peroxyhemiacetal) compounds are formed by addition of an alcohol (a hydroperoxide) to the carbonyl group of an aldehyde. In reactions R3 and R4, $\alpha$-hydroxy ester and $\alpha$-hydroxyperoxy ester are formed from formaldehyde and formic acid (R3), or formaldehyde and performic acid (R4). Reaction R5 is the hydration of formaldehyde in the gas-phase, and R6 is a traditional esterification between a carboxylic acid and an alcohol, in this case yielding methylester and water. In reaction R7, two formic acid molecules form the simplest acid anhydride and water. Reaction $\mathrm{R} 6$ is a concerted reaction without a catalyst, since the product is formed and water removed in the same transition state. However, R6 with an acid catalyst and R7 without a catalyst, are stepwise reactions, where a diol intermediate is formed and water removed in a subsequent step. The structures of the reaction products are illustrated in Figure 1. The studied reaction mechanisms represent some of the most simple dimerization reactions of closed-shell oxidized organic compounds as well as the hydration of a carbonyl group. Thus these reactions can be used as a proxy for reactions between large terpene oxidation products, which consist of the same functional groups.

Furthermore, we studied the ability of the compounds involved in R1-R7 to form hydrogen- 
$\mathbf{R 1} \Upsilon_{\mathrm{O}} \mathrm{OH}$

$\mathrm{R} 2$

R3<smiles>COOCO</smiles>

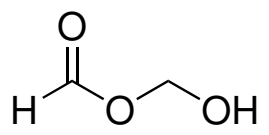

R4

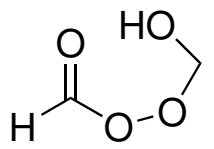

R5

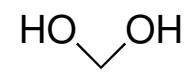

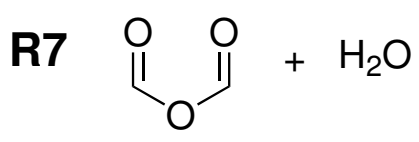

Figure 1: Structures of the final reaction products for reactions R1-R7.

bonded complexes with different catalysts. This includes preliminary hydrogen-bonded dimer formation of reagents, which clusters with the possible catalyst. These reactant clusters are most likely involved in the reaction pathways, since a simultaneous collision of three molecules is unlikely. Additionally, the clustering of catalysts with the obtained dimer products was compared to the cluster formation with monomers. The sampling procedure for obtaining the minimum energy structures for these clusters was performed using the following semiempirically guided technique:

1. In each cluster formation step 200 randomly oriented molecules are distributed around the target molecule/cluster.

2. The structures are initially optimized using the semiempirical PM6 method.

3. The converged structures are optimized at the $\omega \mathrm{B} 97 \mathrm{X}-\mathrm{D} / 6-31+\mathrm{G}^{*}$ level of theory.

4. The structures are sorted, characterized by the total energy, and different conformations are identified.

5. Geometries of conformations within $10 \mathrm{kcal} / \mathrm{mol}$ of the lowest identified conformation are optimized and their frequencies are calculated at the $\omega \mathrm{B} 97 \mathrm{X}-\mathrm{D} / 6-31++\mathrm{G}^{* *}$ level of theory. 6. The structures are sorted based on the Gibbs free energy, and the lowest free energy conformation is used to compare the energetics. 
Using this random sampling procedure for these simple systems, will capture all the conformations and give a good guess for the global free energy minimum structure. However, for studying larger systems, a more detailed exploration of the potential energy surface might be required, such as sampling using molecular dynamics ${ }^{72-74}$ or basin hopping methods. ${ }^{75-77}$ Another promising approach is the recently utilized sampling technique by Temelso et al. based on generating the initial structures using a genetic algorithm. ${ }^{78}$

The molecular structure of all the identified reactants, reactant clusters, transition states, product clusters and products stationary points are shown in the Supporting Information.

\section{3 - Results and Discussion}

\section{1 - Benchmarking}

We have calculated Gibbs free reaction energies and activation free energies for reactions R1-R7. In addition, activation free energies are calculated for reactions R1-R6 using formic acid as a catalyst and for reactions R1-R5 using water as a catalyst. We have only studied the free energies using the harmonic approximation. Temelso et al. have studied the effect of anharmonicity for pure water clusters ${ }^{70}$ and sulfuric acid hydrate clusters. ${ }^{71}$ For both systems the effect of anharmonicity was found to lower the free energy by approximately 0.4 $\mathrm{kcal} / \mathrm{mol}$ per molecule. Figure 2 shows the reaction free energies and activation free energies calculated using the different level of theories. The RI-CCSD(T)-F12/VQZ-F12 level of theory was found to be too computationally demanding for the largest systems investigated. For all reactions, with or without a catalyst, DFT and MP2 give the lowest free energies of

activation $\left(\Delta \mathrm{G}^{\ddagger}\right)$. This is anticipated, since MP2 is known to systematically underestimate reaction barriers. ${ }^{79}$ On the other hand, F12/VDZ calculated on top of the MP2 structures gives the highest $\Delta \mathrm{G}^{\ddagger}$ values. This is due to the fact that results obtained with F12/VDZ are not fully converged to the basis set limit. There is seen a negligible difference $(0.12$ $\mathrm{kcal} / \mathrm{mol}$ or less) between the F12 results obtained with the VTZ and VQZ basis sets. This 
a) No catalyst

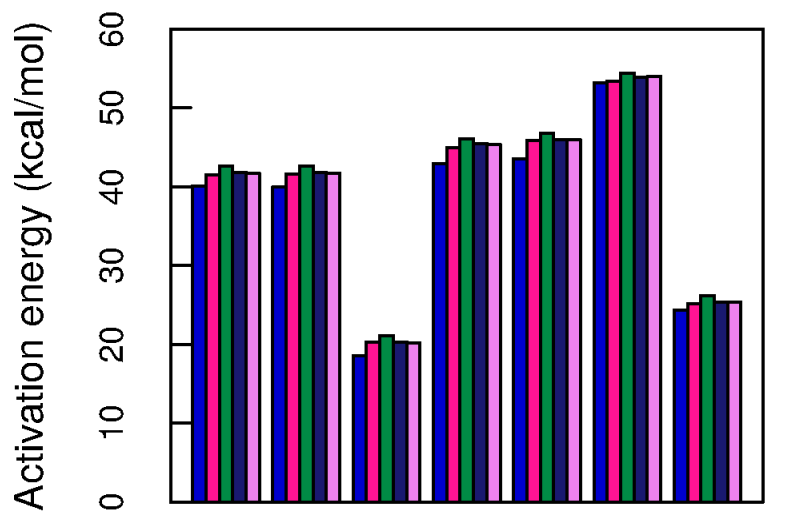

$\begin{array}{llllllll}\text { R1 } & \text { R2 } & \text { R3 } & \text { R4 } & \text { R5 } & \text { R6 } & \text { R7 }\end{array}$ b) $\mathrm{HCOOH}$ catalyst

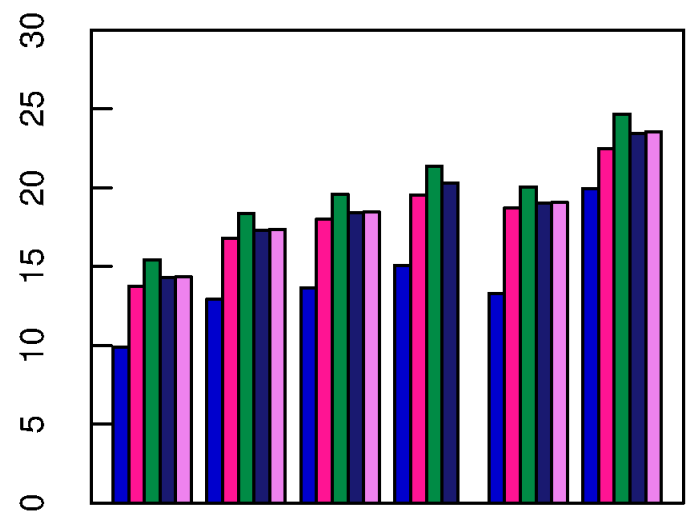

R1 R2 R3 R4 R5 R6 c) $\mathrm{H} 2 \mathrm{O}$ catalyst

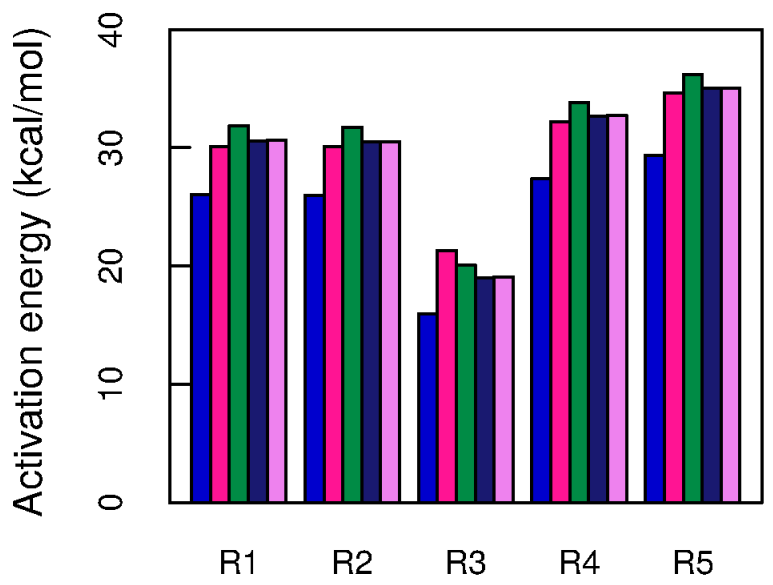

a $\mathrm{wB97X-D}$

口 DLPNO(DFT)

$\square$ F12/DZ(DFT)

- F12/TZ(DFT)

口 F12/QZ(DFT) d) Reaction energies

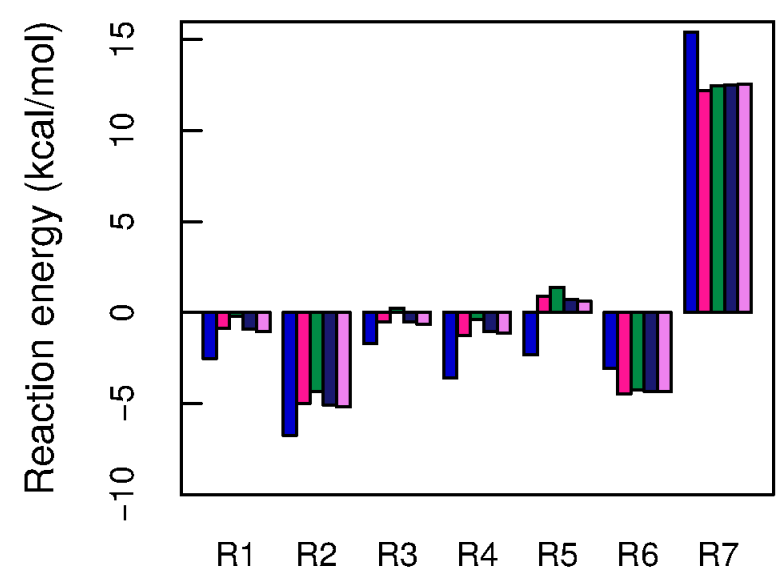

Figure 2: a) Activation free energies $\Delta \mathrm{G}^{\ddagger}$ without a catalyst, b) $\Delta \mathrm{G}^{\ddagger}$ with formic acid as catalyst, c) $\Delta \mathrm{G}^{\ddagger}$ with water as catalyst, and d) free energies of reactions $\Delta \mathrm{G}_{\text {reac }}$. For reactions $\mathrm{R} 6$ and $\mathrm{R} 7$, the first activation free energy is only included. Note the different scales in the graphs. 
implies that the F12/VTZ level of theory is sufficiently accurate for benchmarking purposes. Furthermore, there is only a small difference $(0.49 \mathrm{kcal} / \mathrm{mol}$ or less $)$ to whether these F12 results are computed on top of the DFT or MP2 geometries. This confirms that $\omega$ B97X-D is a suitable DFT functional for obtaining the geometries and vibrational frequencies for the studied reactions. DLPNO single point energies calculated on top of both the DFT and MP2 structures yield results in good agreement with the F12/VQZ method. DLPNO is thus a significant improvement compared to DFT, MP2 and due to the cancellation of errors even F12 with the VDZ basis set.

Table 1 shows the mean absolute errors (MAEs) in activation free energies and reaction free energies compared to the RI-CCSD(T)-F12/VTZ-F12//MP2/aug-cc-pVTZ level of theory. For $\Delta \mathrm{G}_{\text {reac }}$, the MAE's are smaller than for $\Delta \mathrm{G}^{\ddagger}$ especially for the lowest levels of theories. MAEs for DFT and MP2 are above $3 \mathrm{kcal} / \mathrm{mol}$ for $\Delta \mathrm{G}^{\ddagger}$, which implies the need for higher level energy corrections when studying reaction energetics. DLPNO//DFT yield reasonably small deviations of $0.26 \mathrm{kcal} / \mathrm{mol}$ and $0.56 \mathrm{kcal} / \mathrm{mol}$ for $\Delta \mathrm{G}_{\text {reac }}$ and $\Delta \mathrm{G}^{\ddagger}$, respectively, and combined with short computational times justify the further usage of this methodology in our study.

Table 1: Mean absolute errors $(\mathrm{kcal} / \mathrm{mol})$ in activation free energies $\operatorname{MAE}\left(\Delta \mathrm{G}^{\ddagger}\right)$ and reaction free energies $\operatorname{MAE}\left(\Delta \mathrm{G}_{\text {reac }}\right)$. MAEs are calculated for reactions R1-R7 (with and without catalyst) compared to the $\operatorname{CCSD}(\mathrm{T})-\mathrm{F} 12 / \mathrm{VTZ}-$ F12//MP2/aug-cc-pVTZ level of theory.

\begin{tabular}{lcc}
\hline Level of theory & $\operatorname{MAE}\left(\Delta \mathrm{G}^{\ddagger}\right)$ & $\operatorname{MAE}\left(\Delta \mathrm{G}_{\text {reac }}\right)$ \\
\hline DFT & 3.61 & 1.95 \\
DLPNO//DFT & 0.56 & 0.26 \\
F12/VDZ//DFT & 0.86 & 0.58 \\
F12/VTZ//DFT & 0.22 & 0.15 \\
MP2 & 3.09 & 0.58 \\
DLPNO//MP2 & 0.42 & 0.15 \\
F12/VDZ//MP2 & 0.99 & 0.53 \\
\hline
\end{tabular}




\section{2 - Water and Formic Acid Catalysis}

The free energy profiles, with and without catalysts, of reaction R1-R4 are shown in Figure 3. The profiles for R5-R7 are shown in the supporting information. The reactions catalysed by ammonia/sulfuric acid and the formation of the reactant/product clusters, will be discussed in section 3.3 and 3.4, respectively. The calculated activation free energy barriers without catalysts are in all cases high, reaching over $40 \mathrm{kcal} / \mathrm{mol}$, with the only exceptions being R3 and R7. The high free energies of activation can be explained by transition states involving pseudo 4-membered rings, as these structures have a high ring strain. This is not the case with R3 and R7 though, since these reactions have transition states involving 6-membered rings already without catalysts. The larger ring structures reduce the activation free energies, which are 15-20 kcal/mol lower for both R3 and R7 than for other reactions for every level of theory. The catalysts lower the reaction activation free energies by acting as a mediator in the proton shift process, which creates larger pseudo-ring structures in the transition states (see Figure 4(a)). The transition states consist of 8-membered rings (except for R3 with a 10-membered ring) with formic acid as the catalyst, and 6-membered rings (except for R3 with a 8-membered ring) with water as a catalyst. It should be noted that the stabilization of the transition states with catalysts is not solely a geometrical effect originate from the larger pseudo-ring structures. There is also a stabilization from the electronic interaction caused by the formation of hydrogen bonds in the transition states, which will lower the free energy barrier.

Using water as a catalyst lowers the reaction barriers approximately $14-15 \mathrm{kcal} / \mathrm{mol}$ with DFT, and 12-14 kcal/mol with MP2, and free energies of activation calculated with either DLPNO or F12 energy corrections are reduced by $10-12 \mathrm{kcal} / \mathrm{mol}$. Formic acid is evidently a more efficient catalyst than water, as it lowers the barriers on average by $30 \mathrm{kcal} / \mathrm{mol}$ and $27 \mathrm{kcal} / \mathrm{mol}$ for DFT and MP2 optimizations, respectively. These values are slightly

reduced with DLPNO or F12 energy corrections, where the catalytic effect is found to be $26-27 \mathrm{kcal} / \mathrm{mol}$. 


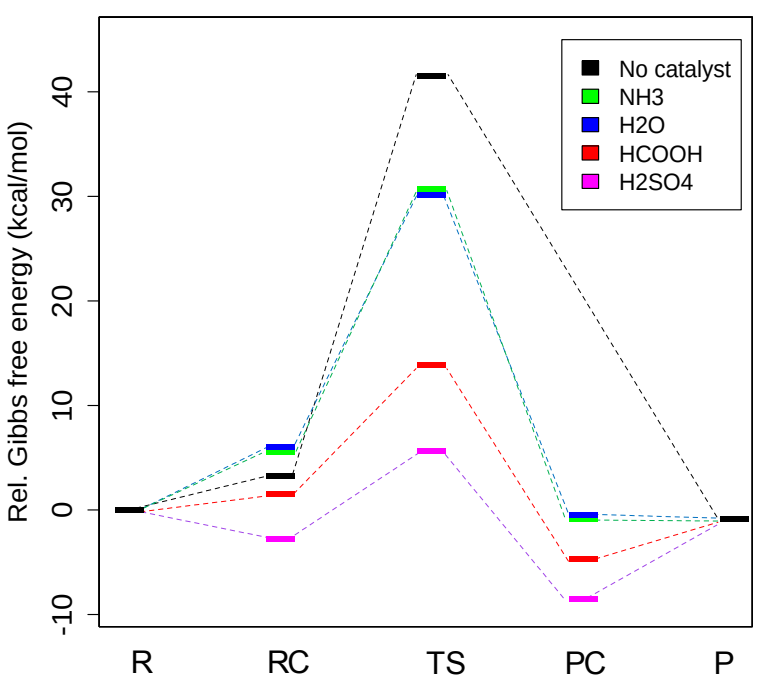

(a)

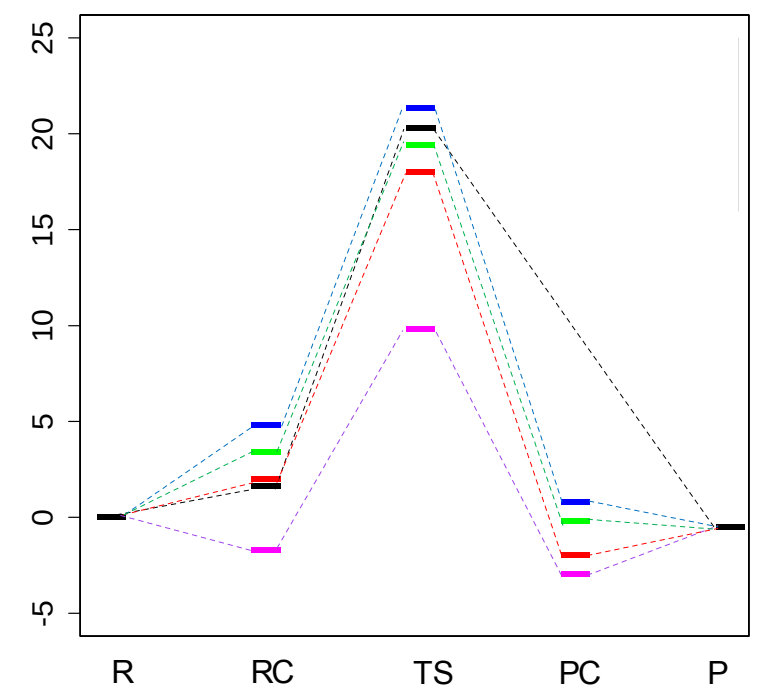

(c)

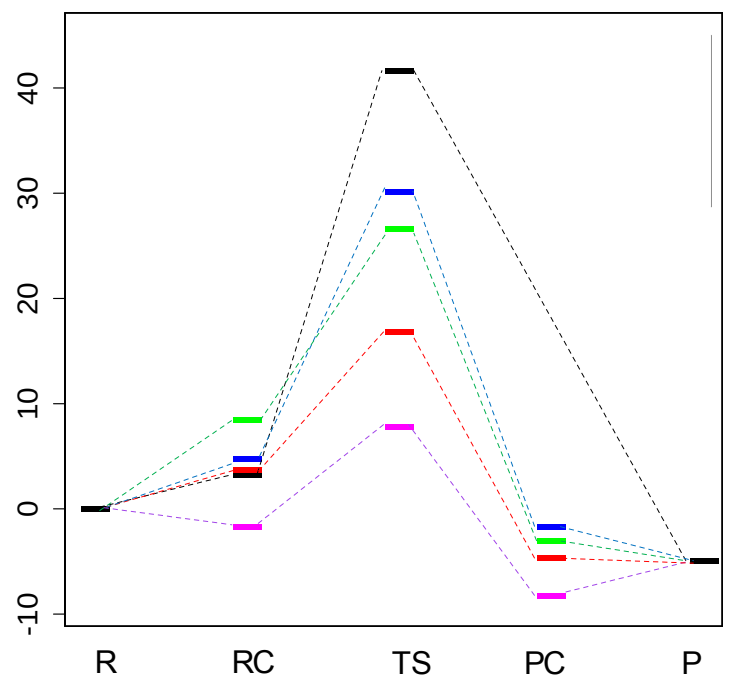

(b)

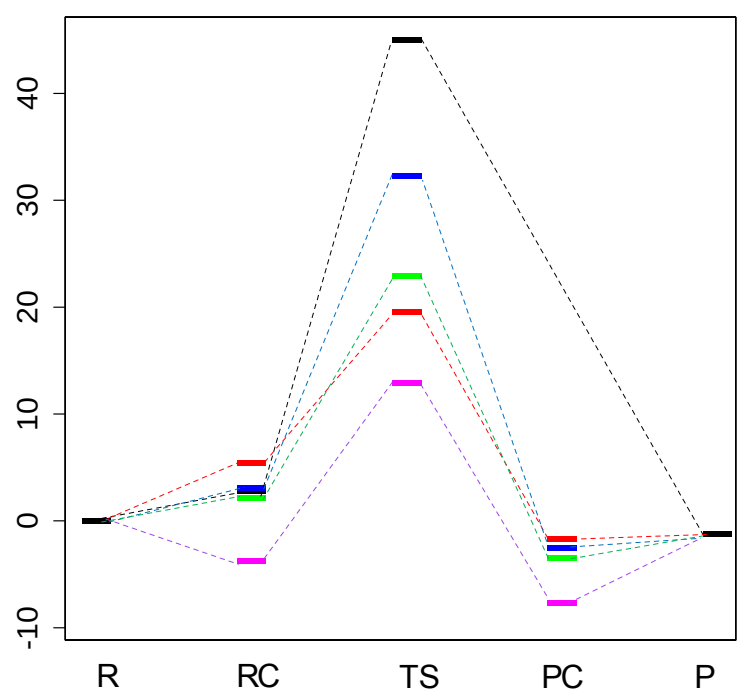

(d)

Figure 3: The free energies profiles for reactions R1-R4 in subfigures a)-d), respectively. The reaction coordinates are the isolated reactants $(\mathrm{R})$, reactant cluster $(\mathrm{RC})$, transition state (TS), product cluster (PC), and isolated products $(\mathrm{P})$. All calculations were performed at the DLPNO-CCSD(T)/aug-cc-pVTZ// $\omega \mathrm{B} 97 \mathrm{X}-\mathrm{D} / 6-31++\mathrm{G}^{* *}$ level of theory. 


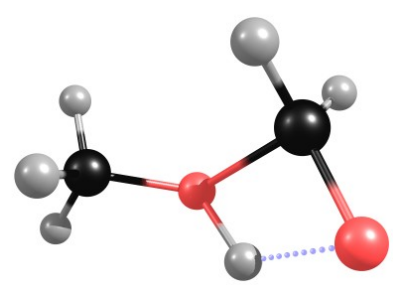

(a)

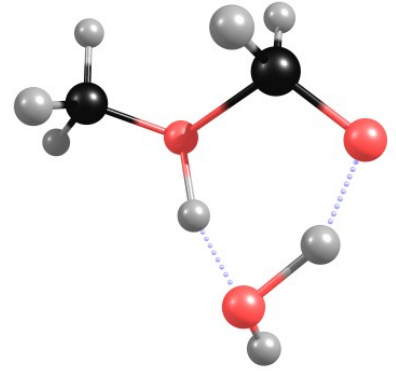

(b)

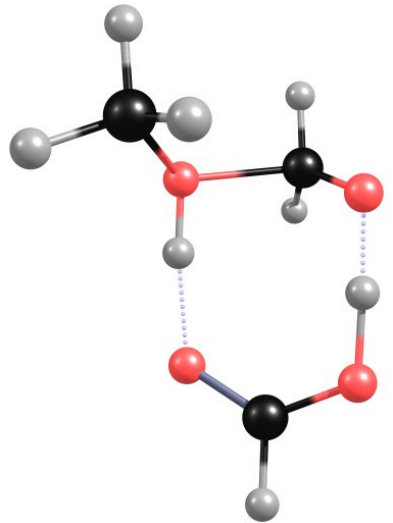

(c)

Figure 4: Transition states for reaction R1 with a) no catalyst, b) water, and c) formic acid as catalyst. The use of a catalyst creates larger pseudo-ring structures and consequently reduces reaction activation free energies.

The effects of catalysts are different for R3, for which the barrier is already significantly smaller than for the rest of the reactions. Using formic acid as a catalyst, the activation free energies are reduced by only $2 \mathrm{kcal} / \mathrm{mol}$ with higher order energy corrections. However, including water as a catalyst seems to have a negative effect on the activation free energies, because $\Delta \mathrm{G}^{\ddagger}$ rises by $2 \mathrm{kcal} / \mathrm{mol}$ when using DLPNO or F12 methods. This is due to the increased rigidity of the system, which in turn decreases entropy. Therefore, water can be excluded as a suitable catalyst for reaction $\mathrm{R} 3$.

As depicted in Figure $2 \mathrm{~d}$ ), the overall reaction Gibbs free energies $\left(\Delta \mathrm{G}_{\text {reac }}\right)$ of the studied dimerization reactions are all negative, except for R5 and R7. Both DFT and MP2 overestimate the reaction energetics for these reactions, and the higher order energy corrections raise the values of $\Delta \mathrm{G}_{\text {reac }}$. Reactions $\mathrm{R} 2$ and $\mathrm{R} 6$ have the most negative reaction Gibbs free energies, which are on average $-5 \mathrm{kcal} / \mathrm{mol}$ and $-4.5 \mathrm{kcal} / \mathrm{mol}$, respectively. The favorable free energy change of peroxyhemiacetal formation in R2 is consistent with previous computational studies, since it has also been observed for a more complex dimer formed from pinonic acid derivatives. ${ }^{38}$ However, the reaction free energies are barely negative for R1, R3, and R4 with approximately $-1 \mathrm{kcal} / \mathrm{mol}$ at the F12/VQZ//MP2 level of theory. The negative signs of the reaction free energy (at $298 \mathrm{~K}$ and 1 atm reference pressure) for 
most of the studied condensation reactions does not imply that the reaction equilibrium in actual atmospheric conditions necessarily favours the dimer products. The organic monomer reactants typically have concentrations on the order of $\mathrm{ppb}_{\mathrm{V}}\left(10^{-9}\right)$. For example for reaction $\mathrm{R} 2$, the computed standard reaction free energy of $-5 \mathrm{kcal} / \mathrm{mol}$ implies a dimensionless equilibrium constant $\left(\exp \left(-\frac{\Delta G_{\text {reac }}}{R T}\right)\right)$ of about 5000 at $298 \mathrm{~K}$. If the monomer equilibrium concentrations (the partial pressure divided by the reference pressure $1 \mathrm{~atm}$ ) are both set to $10^{-9}$, the equilibrium concentration of dimers is thus only $5 \cdot 10^{-15}$, i.e. $5 \mathrm{ppq}$. For reactions such as $\mathrm{R} 6$, the situation is slightly better, as the reaction does not change the number of molecules. However, as the co-product of the reaction is water (with atmospheric concentrations typically on the order of promilles), the equilibrium concentration of dimer products (assuming reactant concentrations in the $\mathrm{ppb}_{\mathrm{V}}$ range) are still at best in the $\mathrm{ppt}_{\mathrm{V}}$ range.

When dissolved in water, formaldehyde is mainly in its hydrated form, ${ }^{80}$ but in the gasphase the formed methanediol cannot form a hydrogen bond network with solvent molecules. In water, these interactions shift the equilibrium towards the diol form. DFT evaluates $\Delta \mathrm{G}_{\text {reac }}$ for $\mathrm{R} 5$ to be negative, while on every other level of theory it is predicted to be slightly greater than zero, with a value of $0.6 \mathrm{kcal} / \mathrm{mol}$ at the F12/VQZ-F12 level of theory for both the MP2 and DFT structures. This result is consistent with previously mentioned studies of accretion reactions for atmospherically relevant aldehydes. ${ }^{27}$ In the condensed phase the formation of an acid anhydride in $\mathrm{R} 7$ is also an equilibrium reaction, which is driven towards the acid anhydride form by removal of water or an excess of one reactant. In the gas-phase this reaction has a high activation barrier, and the isolated reaction products are not thermodynamically favoured over the reactants.

These findings suggests that none of reaction R1-R7 are feasible in the gas-phase, even when using water or formic acid as a catalyst. 


\section{3 - Sulfuric Acid and Ammonia Catalysis}

Different reaction mechanisms were further inspected at the DLPNO//DFT level by including sulfuric acid for reactions R1-R6 and ammonia for R1-R5 as possible catalysts. As stated previously, formic acid is a much more efficient catalyst than water for all reactions. Similar to formic acid, sulfuric acid lowers the transition state barrier via a hydrogen atom transfer mechanism where sulfuric acid simultaneously transfers and accepts one proton. Replacing formic acid with sulfuric acid further reduces activation free energies, and for reactions R1-R3 and R5 they were found to be less than $10 \mathrm{kcal} / \mathrm{mol}$. Dimerization reactions with activation free energies in the sub-10 kcal $/ \mathrm{mol}$ region are likely to take place, and therefore these reactions appear to be the most prominent ones. However, sulfuric acid lowers the activation free energy most drastically for R6, where the barrier height is reduced from 53.4 $\mathrm{kcal} / \mathrm{mol}$ to $14.5 \mathrm{kcal} / \mathrm{mol}$ and for reaction $\mathrm{R} 4$, the activation free energy is reduced to 12.9 $\mathrm{kcal} / \mathrm{mol}$.

Ammonia acts as a weaker catalyst than formic acid or sulfuric acid, but in most cases it has a stronger catalysing effect than water. For reactions R2-R5, the activation barriers are $0.9-9.3 \mathrm{kcal} / \mathrm{mol}$ lower with ammonia than with water. Notably, in contrast to water, ammonia shows a small catalysing effect $(0.9 \mathrm{kcal} / \mathrm{mol})$ for reaction R3. For R1, water lowers the barrier $0.6 \mathrm{kcal} / \mathrm{mol}$ more than ammonia. However, reactions with water or ammonia catalysts are slow, as the free energy barrier vary between 19.4 (R3 with ammonia) and 34.7 $\mathrm{kcal} / \mathrm{mol}$ (R5 with water). The transition states involving water/ammonia or formic/sulfuric acid have very similar structures, which partly explains the similar catalysing effects between the acid molecules or water and ammonia.

\section{4 - Formation of Reactant and Product Clusters}

To obtain a more complete picture of the reactions, different possible reactant and product

clusters (RC and PC, respectively) were studied using the semiempirically guided sampling procedure as discussed in section 2. The reactant clusters include either the reactants or the 
reactants and a catalyst, and the product clusters consist of the product with a catalyst. This means that for reactions without catalyst, $\mathrm{RC}$ is a two-component complex, i.e. the lowest free energy cluster consists of the two reacting monomers. When a catalyst is present, $\mathrm{RC}$ is a three-component cluster consisting two reacting monomers and a catalyst. Also for three-component RCs, the lowest free energy cluster was included in the free energy profile of the reactions. In all cases we use the lowest identified free energy transition state and reactant/product cluster structures. This implies that there is a small molecular rearrangement to reach the lowest free energy structures of the RC and PC from the TS.

The cluster formation of the two reacting monomers is energetically favoured over the isolated molecules only for the hydrogen-bonded formic acid dimer in R7. A co-planar pseudo 8-membered ring structure is created in the complex, with hydrogen bonds between adjacent hydroxyl and carbonyl groups (see Figure 5(a)). This structure is $-3.9 \mathrm{kcal} / \mathrm{mol}$ below the reactants in free energy. The cluster in R6 involves also two hydrogen bonds, but is 0.1 $\mathrm{kcal} / \mathrm{mol}$ higher in free energy than individual reactants. The most favourable geometry between hydrogen bonded atoms is a 180 degree angle, ${ }^{81}$ and since the second H-bond in the pre-reactive complex in R6 is not linear, its stabilizing effect is decreased. For the other reactions, the initial clustering of monomers is 1.6-3.2 kcal/mol higher in Gibbs free energy than isolated reactants. On the contrary, the RC's formed with sulfuric acid are in all cases lower in free energy than the isolated reactants. This is caused by the fact that these clusters have two or three intermolecular hydrogen bonds. For the other catalysts (water, formic acid and ammonia), the free energy required for clustering depends on the reaction. For R1-R5, the RC's with formic acid, water and ammonia are 1.5-3.9 kcal $/ \mathrm{mol}, 3.0-6.4 \mathrm{kcal} / \mathrm{mol}$ and $2.1-8.4 \mathrm{kcal} / \mathrm{mol}$ higher in free energy than the isolated reactants, respectively.

Only for reactions $\mathrm{R} 6$ and $\mathrm{R} 7$ are the pre-reactive complexes with the acid catalysts lower in free energy than the reactants. The fact that the formation free energies of the RC's are positive for water, ammonia, and formic acid catalysed reactions implies that their concentrations will be negligible in the atmosphere. Hence, these reactions are not a feasible 


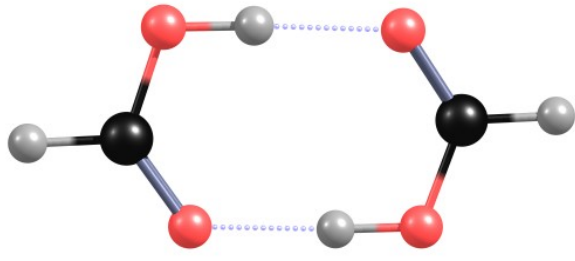

(a)

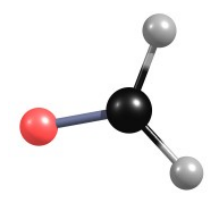

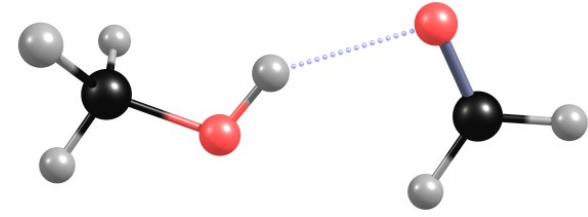

(b)

(c)

Figure 5: Pre-reactive complexes without catalysts include either a) two hydrogen bonds $(\mathrm{R} 7), \mathrm{b})$ one hydrogen bond (R1), or c) no intermolecular hydrogen bonds between reactants (R4).

route to covalently-bound dimer formation at atmospheric conditions.

The potential atmospheric relevance of the studied covalently-bound dimer products can be inspected by comparing the energetics of the RC's and the corresponding PC's. PC's with sulfuric acid or formic acid are lower in free energy than the RC's for R1-R5. For $\mathrm{R} 6$, the $\mathrm{RC}$ with sulfuric acid is $0.8 \mathrm{kcal} / \mathrm{mol}$ lower in free energy than the $\mathrm{PC}$ containing both reaction products and sulfuric acid, and $0.6 \mathrm{kcal} / \mathrm{mol}$ lower than the $\mathrm{PC}$ containing only the ester with sulfuric acid. This is due to the fact that the RC consisting of sulfuric acid, methanol and formic acid has planar hydrogen bonds between the species, while in the product complex the sulfuric acid and the ester are hydrogen bonded to water. Formic acid also binds stronger to the $\mathrm{RC}$ in R6: the hydrogen bonded pseudo-ring structure is increasing the stability of this structure. Due to the strong hydrogen bonded interaction already present in the formic acid dimer, the RC in R7 is also lower in free energy compared to the PC. Additionally, it is notable that even though reactions with ammonia or water catalysts have high free energy barriers, the PC's formed with these catalysts are also lower in free energy than RC's for R1-R5.

It should be noted that the slightly negative Gibbs free energy value only means that 
dimer products bind stronger to the pre-existing cluster than monomers, but for the compound to be stable against evaporation at atmospheric conditions requires the molecular interaction to be very strong. For example, at room temperature and $\mathrm{ppt}_{\mathrm{V}}$ levels of sulfuric acid and organic compounds, a $\Delta G$-value of $-12 \mathrm{kcal} / \mathrm{mol}$ or less would be required to yield a product cluster for which the evaporation rate is slower than the rate of collisions forming the cluster. ${ }^{18}$

\section{5 - Atmospheric Implications}

It is evident from the previous sections that none of the reactions (both with and without catalysts) are feasible in the gas-phase. Determining the possible atmospheric relevance of the studied reactions can be done by calculating the reaction rate coefficients from the activation free energies. Due to the fact that activation free energies without sulfuric acid are in all cases very high, we focus solely on the sulfuric acid catalyzed reactions. First we make the assumption that a single sulfuric acid molecule can represent the cluster surface on which the reaction is occurring. This is a valid assumption for many atmospheric clusters involving sulfuric acid, as one of the $\mathrm{S}-\mathrm{OH}$ groups often lies on the outside of the cluster. This is for instance evident in the study by DePalma et al. ${ }^{82}$ where vacant sulfuric acid binding groups in a $\left(\mathrm{H}_{2} \mathrm{SO}_{4}\right)_{4}\left(\mathrm{NH}_{3}\right)_{4}$ cluster can bind to either pinonaldehyde or pinic acid.

Using the catalyst molecule as a model surface, we can set up the following unimolecular reaction:

$$
\mathrm{RC} \rightarrow \mathrm{TS} \rightarrow \mathrm{PC}
$$

where the reactant cluster $(\mathrm{RC})$ corresponds to the three-component cluster containing two reactant molecules and one sulfuric acid molecule, TS is the transition state, and product cluster (PC) corresponds to the complex of covalently-bound dimer product with sulfuric acid. By using this formulation, the activation free energy barrier is now not the barrier 
from isolated reactants to the TS, but the barrier from the three-molecular RC to the TS as

$$
\Delta G_{\mathrm{barier}}=G_{\mathrm{TS}}-G_{\mathrm{RC}}
$$

The unimolecular rate coefficient for the studied pseudo-surface reactions can be calculated using transition state theory:

$$
k=\frac{k_{\mathrm{B}} T}{h} \exp \left(-\frac{\Delta G_{\text {barrier }}}{R T}\right),
$$

where $k_{\mathrm{B}}$ is the Bolzmann constant, $h$ is the Planck constant, $R$ is the gas constant, $T$ is temperature, and $\Delta G_{\text {barrier }}$ is the Gibbs free energy of the barrier from the TS to the threemolecular RC. It should be noted that this formulation ignores how the RC was formed and is only valid on the surface of a cluster and not in the gas-phase. In other words, we assume that sulfuric acid is present at the cluster surface and that the organic species are simply condensing onto the existing surface, where the reaction will take place. In equation (5) we have neglected tunnelling effects. However, tunnelling effects can be very profound in hydrogen transfer reactions. Kumar et al. ${ }^{83}$ recently studied the decomposition of methanediol corresponding to the reverse reaction of reaction $\mathrm{R} 5$. They found that the effect of proton tunnelling could enhance the rate constant by up to 9 orders of magnitude for the unimolecular, uncatalyzed decomposition at 200 K. For the bimolecular, catalyzed reactions Kumar et al. found tunnelling factors in the range of 2.9-268.2 and 1.4-6.3 at 200 and $300 \mathrm{~K}$, respectively.

Table 2 shows the calculated free energy barriers and rate coefficients for reactions R1R6 with sulfuric acid as a catalyst at the DLPNO//DFT level of theory. The Gibbs free energy barrier for reaction $\mathrm{R} 1$ is the lowest with a value of $8.4 \mathrm{kcal} / \mathrm{mol}$, and yielding a reaction rate constant of $4 \cdot 10^{8} s^{-1}$. Reactions R2, R3, and R5 also have relative low Gibbs free energy barriers with values of $9.5,11.6$, and $11.9 \mathrm{kcal} / \mathrm{mol}$, respectively. This yields reaction rate constants of $6 \cdot 10^{5}, 2 \cdot 10^{4}$, and $1 \cdot 10^{4} \mathrm{~s}^{-1}$, respectively. These relatively high 
Table 2: Calculated Gibbs free energy barriers and rate coefficients for dimerformation reactions occurring on a sulfuric acid cluster surface.

\begin{tabular}{lcc}
\hline Reaction & $\Delta G_{\text {barrier }}(\mathrm{kcal} / \mathrm{mol})$ & $k\left(\mathrm{~s}^{-1}\right)$ \\
\hline R1 & 8.4 & $4 \cdot 10^{8}$ \\
R2 & 9.5 & $6 \cdot 10^{5}$ \\
R3 & 11.6 & $2 \cdot 10^{4}$ \\
R4 & 16.7 & 3 \\
R5 & 11.9 & $1 \cdot 10^{4}$ \\
R6 (TS1) & 22.2 & $3 \cdot 10^{-4}$ \\
\hline
\end{tabular}

rate constants implies that reactions $\mathrm{R} 1, \mathrm{R} 2, \mathrm{R} 3$, and $\mathrm{R} 5$ might be able to take place at a sulfuric acid cluster interface. Reaction R4 has a Gibbs free energy barrier of $16.7 \mathrm{kcal} / \mathrm{mol}$ and the reaction rate constant is $3 \mathrm{~s}^{-1}$, meaning that this reaction is not likely to have an atmospheric impact. Reaction R6 has the highest reaction free energy barrier with a value of $22.2 \mathrm{kcal} / \mathrm{mol}$, which leads to reaction rate constant of $3 \cdot 10^{-4} \mathrm{~s}^{-1}$ and this reaction is certainly not feasible in atmospheric conditions.

\section{4 - Conclusions}

We have studied the dimerization reactions between small common oxidized organic molecules to elucidate the thermodynamics and kinetics of covalently-bound dimer formation. The effect of different catalysts (water, ammonia, formic acid and sulfuric acid) on the reaction energetics, and the ability of reactants as well as reaction products to form complexes with the catalysts was explored. These dimerization reactions were found not to be kinetically feasible in the gas-phase without an acid catalyst, and especially sulfuric acid lowers the activation free energy barriers to less than $10 \mathrm{kcal} / \mathrm{mol}$.

The dimer products form thermodynamically more favourable clusters with sulfuric acid than the corresponding reactants. Furthermore, the product clusters are also found to be lower in free energy than the isolated reaction products for reactions R1-R5. However, none of the product clusters are thermodynamically stable against evaporation at atmospheric conditions. This is because the interaction between a single functional group and a single 
sulfuric acid is not strong enough.

Through dimer formation reactions, molecules are able to increase their molecular weight and the amount of functional groups, thus reducing their vapour pressures. If the reactions take place for example on the surface of a cluster, the dimer products are less likely to evaporate due to their decreased volatility, and more likely to stick onto the existing cluster. This study provides encouraging results for further explorations within this field, and provides a starting point for studies of larger systems including, for example, terpene oxidation products.

\section{Acknowledgement}

We thank the Academy of Finland and ERC project 692891-DAMOCLES for funding, and the CSC-IT Center for Science in Espoo, Finland, for computational resources. J. E. thanks the Carlsberg and Villum foundation for financial support.

\section{Supporting Information Available}

- All xyz-files of the geometry optimized structures at the $\omega \mathrm{B} 97 \mathrm{X}-\mathrm{D} / 6-31++\mathrm{G}^{* *}$ level of theory.

- Figures of the reactants, reactant clusters, transition states, product clusters and products stationary points.

- MP2 benchmark results.

- The Gibbs free energy profiles of reaction R5-R7.

This material is available free of charge via the Internet at http://pubs.acs.org/. 


\section{References}

(1) Stevens, B.; Feingold, G. Untangling Aerosol Effects on Clouds and Precipitation in a Buffered System. Nature 2009, 461, 607-613.

(2) Kulmala, M.; Riipinen, I.; Sipilä, M.; Manninen, H. E.; Petäjä, T.; Junninen, H.; Maso, M. D.; Mordas, G.; Mirme, A.; Vana, M. et al. Toward Direct Measurement of Atmospheric Nucleation. Science 2007, 318, 89-92.

(3) Kulmala, M.; Kontkanen, J.; Junninen, H.; Lehtipalo, K.; Manninen, H. E.; Nieminen, T.; Petäjä, T.; Sipilä, M.; Schobesberger, S.; Rantala, P. et al. Direct Observations of Atmospheric Aerosol Nucleation. Science 2013, 339, 943-946.

(4) Lim, H.-J.; Turpin, B. J. Origins of Primary and Secondary Organic Aerosol in Atlanta: Results of Time-Resolved Measurements during the Atlanta Supersite Experiment. Environ. Sci. Technol. 2002, 36, 4489-4496.

(5) Turpin, B. J.; Saxena, P.; Andrews, E. Measuring and Simulating Particulate Organics in the Atmosphere: Problems and Prospects. Atmos. Environ. 2000, 34, 2983 - 3013.

(6) Hallquist, M.; Wenger, J. C.; Baltensperger, U.; Rudich, Y.; Simpson, D.; Claeys, M.; Dommen, J.; Donahue, N. M.; George, C.; Goldstein, A. H. et al. The Formation, Properties and Impact of Secondary Organic Aerosol: Current and Emerging Issues. Atmospheric Chemistry and Physics 2009, 9, 5155-5236.

(7) Kurtén, T.; Torpo, L.; Ding, C.-G.; Vehkamäki, H.; Sundberg, M. R.; Laasonen, K.; Kulmala, M. A Density Functional Study on Water - Sulfuric Acid - Ammonia Clusters and Implications for Atmospheric Cluster Formation. J. Geophys. Res. Atmos. 2007, 112, D04210.

(8) Loukonen, V.; Kurtén, T.; Ortega, I. K.; Vehkamäki, H.; Pádua, A. A. H.; Sellegri, K.; Kulmala, M. Enhancing Effect of Dimethylamine in Sulfuric Acid Nucleation in the 
Presence of Water - A Computational Study. Atmos. Chem. Phys. 2010, 10, 49614974.

(9) Olenius, T.; Kupiainen-Määttä, O.; Ortega, I. K.; Kurtén, T.; Vehkamäki, H. Free Energy Barrier in the Growth of Sulfuric Acid - Ammonia and Sulfuric Acid - Dimethylamine Clusters. J. Chem. Phys. 2013, 139, 084312.

(10) Schobesberger, S.; Junninen, H.; Bianchi, F.; Lönn, G.; Ehn, M.; Lehtipalo, K.; Dommen, J.; Ehrhart, S.; Ortega, I. K.; Franchin, A. et al. Molecular Understanding of Atmospheric Particle Formation from Sulfuric Acid and Large Oxidized Organic Molecules. Proc. Natl. Acad. Sci. 2013, 110, 17223-17228.

(11) Xu, Y.; Nadykto, A. B.; Yu, F.; Herb, J.; Wang, W. Interaction between Common Organic Acids and Trace Nucleation Species in the Earth's Atmosphere. J. Phys. Chem. A 2010, 114, 387-396.

(12) Nadykto, A. B.; Yu, F.; Jakovleva, M. V.; Herb, J.; Xu, Y. Amines in the Earth's Atmosphere: A Density Functional Theory Study of the Thermochemistry of PreNucleation Clusters. Entropy 2011, 13, 554-569.

(13) Kirkby, J.; Duplissy, J.; Sengupta, K.; Frege, C.; Gordon, H.; Williamson, C.; Heinritzi, M.; Simon, M.; Yan, C.; Almeida, J. et al. Ion-induced Nucleation of Pure Biogenic Particles. Nature 2016, 533, 521-526.

(14) Riccobono, F.; Schobesberger, S.; Scott, C. E.; Dommen, J.; Ortega, I. K.; Rondo, L.; Almeida, J.; Amorim, A.; Bianchi, F.; Breitenlechner, M. et al. Oxidation Products of Biogenic Emissions Contribute to Nucleation of Atmospheric Particles. Science 2014, $344,717-721$.

(15) Elm, J.; Myllys, N.; Hyttinen, N.; Kurtén, T. Computational Study of the Clustering of a Cyclohexene Autoxidation Product $\mathrm{C}_{6} \mathrm{H}_{8} \mathrm{O}_{7}$ with Itself and Sulfuric Acid. J. Phys. Chem. A 2015, 119, 8414-8421. 
(16) Elm, J.; Myllys, N.; Luy, J.-N.; Kurtén, T.; Vehkamäki, H. The Effect of Water and Bases on the Clustering of a Cyclohexene Autoxidation Product $\mathrm{C}_{6} \mathrm{H}_{8} \mathrm{O}_{7}$ with Sulfuric Acid. J. Phys. Chem. A 2016, 120, 2240-2249.

(17) Kurtén, T.; Tiusanen, K.; Roldin, P.; Rissanen, M.; Luy, J.-N.; Boy, M.; Ehn, M.; Donahue, N. $\alpha$-Pinene Autoxidation Products May Not Have Extremely Low Saturation Vapor Pressures Despite High O:C Ratios. J. Phys. Chem. A 2016, 120, 2569-2582.

(18) Elm, J.; Myllys, N.; Kurtén, T. What Is Required for Highly Oxidized Molecules To Form Clusters with Sulfuric Acid? J. Phys. Chem. A 2017, 121, 4578-4587.

(19) Elm, J.; Myllys, N.; Olenius, T.; Halonen, R.; Kurtén, T.; Vehkamaki, H. Formation of Atmospheric Molecular Clusters Consisting of Sulfuric Acid and $\mathrm{C}_{8} \mathrm{H}_{12} \mathrm{O}_{6}$ tricarboxylic acid. Phys. Chem. Chem. Phys. 2017, 19, 4877-4886.

(20) Myllys, N.; Olenius, T.; Kurtén, T.; Vehkamäki, H.; Riipinen, I.; Elm, J. Effect of Bisulfate, Ammonia, and Ammonium on the Clustering of Organic Acids and Sulfuric Acid. J. Phys. Chem. A 2017, 121, 4812-4824.

(21) Altieri, K.; Seitzinger, S.; Carlton, A.; Turpin, B.; Klein, G.; Marshall, A. Oligomers Formed Through In-cloud Methylglyoxal Reactions: Chemical Composition, Properties, and Mechanisms Investigated by Ultra-high Resolution FT-ICR Mass Spectrometry. Atmos. Environ. 2008, 42, 1476 - 1490.

(22) Denkenberger, K. A.; Moffet, R. C.; Holecek, J. C.; Rebotier, T. P.; Prather, K. A. RealTime, Single-Particle Measurements of Oligomers in Aged Ambient Aerosol Particles. Environ. Sci. Technol. 2007, 41, 5439-5446.

(23) Mohr, C.; Lopez-Hilfiker, F. D.; Yli-Juuti, T.; Heitto, A.; Lutz, A.; Hallquist, M.; D’Ambro, E. L.; Rissanen, M. P.; Hao, L.; Schobesberger, S. et al. Ambient Observations of Dimers from Terpene Oxidation in the Gas Phase: Implications for New Particle Formation and Growth. Geophys. Res. Lett. 2017, 44, 2958-2966. 
(24) Kalberer, M.; Sax, M.; Samburova, V. Molecular Size Evolution of Oligomers in Organic Aerosols Collected in Urban Atmospheres and Generated in a Smog Chamber. Environ. Sci. Technol. 2006, 40, 5917-5922.

(25) Gao, S.; Ng, N. L.; Keywood, M.; Varutbangkul, V.; Bahreini, R.; Nenes, A.; He, J.; Yoo, K. Y.; Beauchamp, J. L.; Hodyss, R. P. et al. Particle Phase Acidity and Oligomer Formation in Secondary Organic Aerosol. Environ. Sci. Technol. 2004, 38, 6582-6589.

(26) Kourtchev, I.; Giorio, C.; Manninen, A.; Wilson, E.; Mahon, B.; Aalto, J.; Kajos, M.; Venables, D.; Ruuskanen, T.; Levula, J. et al. Enhanced Volatile Organic Compounds Emissions and Organic Aerosol Mass Increase the Oligomer Content of Atmospheric Aerosols. Sci. Rep. 2016, 6, 35038.

(27) Barsanti, K. C.; Pankow, J. F. Thermodynamics of the formation of atmospheric organic particulate matter by accretion reactions-Part 1: aldehydes and ketones. Atmos. Environ. 2004, 38, 4371-4382.

(28) Barsanti, K. C.; Pankow, J. F. Thermodynamics of the formation of atmospheric organic particulate matter by accretion reactions-2. Dialdehydes, methylglyoxal, and diketones. Atmos. Environ. 2005, 39, 6597-6607.

(29) Barsanti, K. C.; Pankow, J. F. Thermodynamics of the formation of atmospheric organic particulate matter by accretion reactions-Part 3: Carboxylic and dicarboxylic acids. Atmos. Environ. 2006, 40, 6676-6686.

(30) Zhang, X.; McVay, R. C.; Huang, D. D.; Dalleska, N. F.; Aumont, B.; Flagan, R. C.; Seinfeld, J. H. Formation and Evolution of Molecular Products in $\alpha$-pinene Secondary Organic Aerosol. Proc. Natl. Acad. Sci. U.S.A. 2015, 112, 14168-14173.

(31) Krizner, H. E.; De Haan, D. O.; Kua, J. Thermodynamics and Kinetics of Methylglyoxal Dimer Formation: A Computational Study. J. Phys. Chem. A 2009, 113, 6994-7001. 
(32) Yasmeen, F.; Vermeylen, R.; Szmigielski, R.; Iinuma, Y.; Böge, O.; Herrmann, H.; Maenhaut, W.; Claeys, M. Terpenylic Acid and Related Compounds: Precursors for Dimers in Secondary Organic Aerosol from the Ozonolysis of $\alpha$ and $\beta$-pinene. Atmos. Chem. Phys. 2010, 10, 9383-9392.

(33) Camredon, M.; Hamilton, J. F.; Alam, M. S.; Wyche, K. P.; Carr, T.; White, I. R.; Monks, P. S.; Rickard, A. R.; Bloss, W. J. Distribution of Gaseous and Particulate Organic Composition During Dark $\alpha$-pinene Ozonolysis. Atmos. Chem. Phys. 2010, 10, 2893-2917.

(34) Kristensen, K.; Enggrob, K. L.; King, S. M.; Worton, D. R.; Platt, S. M.; Mortensen, R.; Rosenoern, T.; Surratt, J. D.; Bilde, M.; Goldstein, A. H. et al. Formation and Occurrence of Dimer Esters of Pinene Oxidation Products in Atmospheric Aerosols. Atmos. Chem. Phys. 2013, 13, 3763-3776.

(35) Kristensen, K.; Cui, T.; Zhang, H.; Gold, A.; Glasius, M.; Surratt, J. D. Dimers in $\alpha$-pinene Secondary Organic Aerosol: Effect of Hydroxyl Radical, Ozone, Relative Humidity and Aerosol Acidity. Atmos. Chem. Phys. 2014, 14, 4201-4218.

(36) Kristensen, K.; Watne, A. K.; Hammes, J.; Lutz, A.; Petäjä, T.; Hallquist, M.; Bilde, M.; Glasius, M. High-Molecular Weight Dimer Esters Are Major Products in Aerosols from $\alpha$-Pinene Ozonolysis and the Boreal Forest. Environ. Sci. Technol. Lett. 2016, 3, 280-285.

(37) Krizner, H. E.; Haan, D. O. D.; Kua, J. Thermodynamics and Kinetics of Methylglyoxal Dimer Formation: A Computational Study. J. Phys. Chem. A 2009, 113, 6994-7001.

(38) Depalma, J. W.; Horan, A. J.; IV, W. A. H.; Johnston, M. V. Thermodynamics of Oligomer Formation: Implications for Secondary Organic Aerosol Formation and Reactivity. Phys. Chem. Chem. Phys 2013, 15, 6935-6944. 
(39) Louie, M. K.; Francisco, J. S.; Verdicchio, M.; Klippenstein, S. J.; Sinha, A. Dimethylamine Addition to Formaldehyde Catalyzed by a Single Water Molecule: A Facile Route for Atmospheric Carbinolamine Formation and Potential Promoter of Aerosol Growth. J. Phys. Chem. A 2016, 120, 1358-1368.

(40) Patil, M. P.; Sunoj, R. B. Insights on Co-Catalyst-Promoted Enamine Formation between Dimethylamine and Propanal through Ab Initio and Density Functional Theory Study. J. Org. Chem. 2007, 72, 8202-8215.

(41) Sayer, J. M.; Jencks, W. P. Mechanism and Catalysis of 2-methyl-3-thiosemicarbazone Formation. Second Change in Rate-determining Step and Evidence for a Stepwise Mechanism for Proton Transfer in a Simple Carbonyl Addition Reaction. J. Am. Chem. Soc. 1973, 95, 5637-5649.

(42) Duporté, G.; Riva, M.; Parshintsev, J.; Heikkinen, E.; Barreira, L. M.; Myllys, N.; Heikkinen, L.; Hartonen, K. M.; Kulmala, M.; Ehn, M. et al. Chemical Characterization of Gas- and Particle-Phase Products from the Ozonolysis of $\alpha$-Pinene in the Presence of Dimethylamine. Environ. Sci. Technol. 2017, 51, 5602-5610.

(43) Sunoj, R. B.; Anand, M. Microsolvated Transition State Models for Improved Insight Into Chemical Properties and Reaction Mechanisms. Phys. Chem. Chem. Phys. 2012, 14, 12715-12736.

(44) Rypkema, H. A.; Sinha, A.; Fransisco, J. S. Carboxylic Acid Catalyzed Hydration of Acetaldehyde. J. Phys. Chem. A 2015, 119, 4581-4588.

(45) Hazra, M. K.; Fransisco, J. S.; Sinha, A. Gas Phase Hydrolysis of Formaldehyde To Form Methanediol: Impact of Formic Acid Catalysis. J. Phys. Chem. A 2013, 117, $11704-11710$.

(46) Hazra, M. K.; Fransisco, J. S.; Sinha, A. Hydrolysis of Glyoxal in Water-Restricted En- 
vironments: Formation of Organic Aerosol Precursors through Formic Acid Catalysis. J. Phys. Chem. A 2014, 118, 4095-4105.

(47) Long, B.; Tan, X.-F.; Chang, C.-R.; Zhao, W.-X.; Long, Z.-W.; Ren, D.-S.; ; Zhang, W.J. Catalyzed Hydrolysis of Formaldehyde and Formaldehyde with Sulfuric Acid and H2SO4 $\cdots$ H2O Complex. J. Phys. Chem. A 2013, 117, 5106-5116.

(48) Liu, L.; Zhang, X.; Li, Z.; Zhang, Y.; Ge, M. Gas-phase Hydration of Glyoxylic Acid: Kinetics and Atmospheric Implications. Chemosphere 2017, 186, 430-437.

(49) Frisch, M. J.; Trucks, G. W.; Schlegel, H. B.; Scuseria, G. E.; Robb, M. A.; Cheeseman, J. R.; Scalmani, G.; Barone, V.; Mennucci, B.; Petersson, G. A. et al. Gaussian09 Revision D.01. Gaussian Inc. Wallingford CT 2009.

(50) Frisch, M. J.; Trucks, G. W.; Schlegel, H. B.; Scuseria, G. E.; Robb, M. A.; Cheeseman, J. R.; Scalmani, G.; Barone, V.; Petersson, G. A.; Nakatsuji, H. et al. Gaussian16 Revision A.03. Gaussian Inc. Wallingford CT 2016.

(51) Neese, F. The ORCA program system. Wiley Interdiscip. Rev. Comput. Mol. Sci. 2012, 2, 73-78.

(52) Chai, J.-D.; Head-Gordon, M. Long-range Corrected Hybrid Density Functionals with Damped Atom-atom Dispersion Corrections. Phys. Chem. Chem. Phys. 2008, 10, 66156620.

(53) Grimme, S.; Antony, J.; Ehrlich, S.; Krieg, H. A Consistent and Accurate Ab Initio Parametrization of Density Functional Dispersion Correction (DFT-D) for the 94 Elements H-Pu. J. Chem. Phys. 2010, 132.

(54) Krishnan, R.; Binkley, J. S.; Seeger, R.; Pople, J. A. Self-consistent Molecular Orbital Methods. XX. A Basis Set for Correlated Wave Functions. J. Chem. Phys. 1980, 72, $650-654$. 
(55) Hehre, W. J.; Ditchfield, R.; Pople, J. A. Self-Consistent Molecular Orbital Methods. XII. Further Extensions of Gaussian - Type Basis Sets for Use in Molecular Orbital Studies of Organic Molecules. J. Chem. Phys. 1972, 56, 2257-2261.

(56) Frisch, M. J.; Pople, J. A.; Binkley, J. S. Self-consistent Molecular Orbital Methods 25. Supplementary Functions for Gaussian Basis Sets. J. Chem. Phys. 1984, 80, 3265-3269.

(57) Chai, J.-D.; Head-Gordon, M. Long-range Corrected Hybrid Density Functionals with Damped Atom-atom Dispersion Corrections. Phys. Chem. Chem. Phys. 2008, 10, 66156620.

(58) Elm, J.; Mikkelsen, K. V. Computational Approaches for Efficiently Modelling of Small Atmospheric Clusters. Chem. Phys. Lett. 2014, 615, 26 - 29.

(59) Myllys, N.; Elm, J.; Kurtén, T. Density Functional Theory Basis Set Convergence of Sulfuric Acid-containing Molecular Clusters. Comp. Theor. Chem. 2016, 1098, 1 - 12.

(60) Riplinger, C.; Neese, F. An Efficient and Near Linear Scaling Pair Natural Orbital Based Local Coupled Cluster Method. J. Chem. Phys. 2013, 138, 034106.

(61) Riplinger, C.; Sandhoefer, B.; Hansen, A.; Neese, F. Natural Triple Excitations in Local Coupled Cluster Calculations with Pair Natural Orbitals. J. Chem. Phys. 2013, 139, 134101.

(62) Riplinger, C.; Pinski, P.; Becker, U.; Valeev, E. F.; Neese, F. Sparse Maps - A Systematic Infrastructure for Reduced-scaling Electronic Structure Methods. II. Linear Scaling Domain Based Pair Natural Orbital Coupled Cluster Theory. J. Chem. Phys 2016, $144,024109$.

(63) Dunning, T. H. Gaussian Basis Sets for use in Correlated Molecular Calculations. I. The Atoms Boron through Neon and Hydrogen. J. Chem. Phys. 1989, 90, 1007-1023. 
(64) Kendall, R. A.; Dunning, T. H.; Harrison, R. J. Electron Affinities of the Firstrow Atoms Revisited. Systematic Basis Sets and Wave Functions. J. Chem. Phys. 1992, 96, 6796-6806.

(65) Myllys, N.; Elm, J.; Halonen, R.; Kurtén, T.; Vehkamäki, H. Coupled Cluster Evaluation of the Stability of Atmospheric Acid - Base Clusters with up to 10 Molecules. J. Phys. Chem. A 2016, 120,621-630.

(66) Werner, H.; Adler, T. B.; Manby, F. R. General Orbital Invariant MP2-F12 Theory. J. Chem. Phys. 2007, 126, 164102.

(67) Adler, T. B.; Knizia, G.; Werner, H. A Simple and Efficient CCSD(T)-F12 Approximation. J. Chem. Phys. 2007, 127, 221106.

(68) Valeev, E. F. Coupled-cluster Methods with Perturbative Inclusion of Explicitly Correlated Terms: A Preliminary Investigation. Phys. Chem. Chem. Phys. 2008, 10, 106113.

(69) Peterson, K. A.; Adler, T. B.; Werner, H. Systematically Convergent Basis Sets for Explicitly Correlated Wavefunctions: The Atoms H, He, B-Ne, and Al-Ar. J. Chem. Phys. 2008, 128, 084102.

(70) Temelso, B.; Archer, K. A.; Shields, G. C. Benchmark Structures and Binding Energies of Small Water Clusters with Anharmonicity Corrections. J. Phys. Chem. A. 2011, $115,12034-12046$.

(71) Temelso, B.; Morrell, T. E.; Shields, R. M.; Allodi, M. A.; Wood, E. K.; Kirschner, K. N.; Castonguay, T. C.; Archer, K. A.; Shields, G. C. Quantum Mechanical Study of Sulfuric Acid Hydration: Atmospheric Implications. J. Phys. Chem. A. 2012, 116, 2209-2224. 
(72) Loukonen, V.; Kurtén, T.; Ortega, I. K.; Vehkamäki, H.; Pádua, A. A. H.; Sellegri, K.; Kulmala, M. Enhancing Effect of Dimethylamine in Sulfuric Acid Nucleation in the Presence of Water - A Computational Study. Atmos. Chem. Phys. 2010, 10, 49614974.

(73) Shields, R. M.; Temelso, B.; Archer, K. A.; Morrell, T. E.; Shields, G. C. Accurate Predictions of Water Cluster Formation, $(\mathrm{H} 2 \mathrm{O}) \mathrm{n}=2-10$. J. Phys. Chem. A. 2010, 114, $11725-11737$.

(74) Husar, D. E.; Temelso, B.; Ashworth, A. L.; Shields, G. C. Hydration of the Bisulfate Ion: Atmospheric Implications. J. Phys. Chem. A. 2012, 116, 5151-5163.

(75) Peng, X.-Q.; Liu, Y.-R.; Huang, T.; Jiang, S.; Huang, W. Interaction of Gas Phase Oxalic Acid with Ammonia and its Atmospheric ImplicationsâĂă. Phys. Chem. Chem. Phys. 2015, 17, 9552-9563.

(76) Miao, S.-K.; Jiang, S.; Chen, J.; Ma, Y.; Zhu, Y.-P.; Wen, Y.; Zhang, M.-M.; Huang, W. Hydration of a Sulfuric Acid-oxalic Acid Complex: Acid Dissociation and its Atmospheric ImplicationâĂă. RSC Adv. 2015, 5, 48638-48646.

(77) Chen, J.; Jiang, S.; Liu, Y.-R.; Huang, T.; Wang, C.-Y.; Miao, S.-K.; Wang, Z.-Q.; Zhang, Y.; Huang, W. Interaction of Oxalic Acid with Dimethylamine and its Atmospheric ImplicationsâĂă. RSC Adv. 2017, 7, 6374-6388.

(78) Temelso, B.; Morrison, E. F.; Speer, D. L.; Cao, B. C.; Appiah-Padi, N. A.; Kim, G.; Shields, G. C. Effect of Mixing Ammonia and Alkylamines on Sulfate Aerosol Formation. J. Phys. Chem. A 2018, DOI: 10.1021/acs.jpca.7b11236.

(79) Lynch, B. J.; Truhlar, D. G. Small Representative Benchmarks for Thermochemical Calculations. J. Phys. Chem. A 2003, 107, 8996-8999. 
(80) Greenzaid, P.; Luz, Z.; Samuel, D. A Nuclear Magnetic Resonance Study of the Reversible Hydration of Aliphatic Aldehydes and Ketones. I. Oxygen-17 and Proton Spectra and Equilibrium Constants. J. Am. Chem. Soc 1967, 89, 749-756.

(81) Pakiari, A.; Eskandari, K. The Chemical Nature of Very Strong Hydrogen Bonds in some Categories of Compounds. J. Mol. Struct.: THEOCHEM 2006, 759, 51-60.

(82) DePalma, J. W.; Wang, J.; Wexler, A. S.; Johnston, M. V. Growth of Ammonium Bisulfate Clusters by Adsorption of Oxygenated Organic Molecules. J. Phys. Chem. A 2015, 119, 11191-11198.

(83) Kumar, M.; Anglada, J. M.; Francisco, J. S. Role of Proton Tunneling and Metal-Free Organocatalysis in the Decomposition of Methanediol: A Theoretical Study. J. Phys. Chem. A 2017, 121, 4318ấ̌́s-4325. 
Graphical TOC Entry

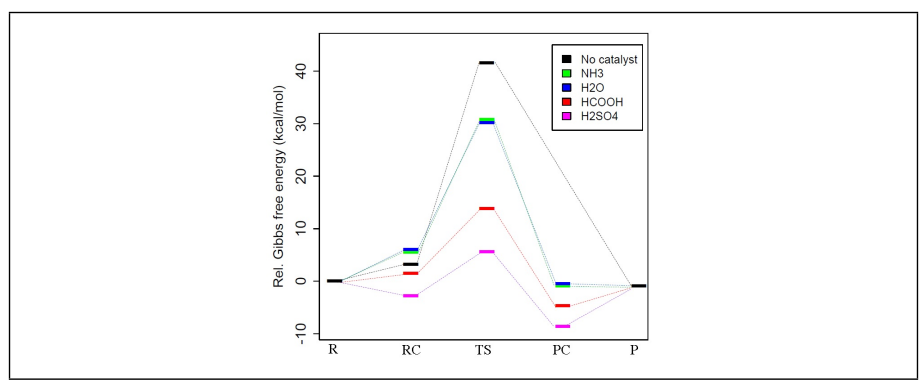

